\section{The Initial Success Rate of Cardiopulmonary Resuscitation and Its Associated Factors among Intensive Care Unit Patients in a Tertiary Hospital in Saudi Arabia}

\section{Abstract}

Background: Cardiopulmonary Resuscitation (CPR) details of 1350 patients from an Intensive Care Unit, tertiary care hospital with 1500 bed capacity in Riyadh, Kingdom of Saudi Arabia was analysed.

Objectives: (1) To determine the initial success rate of Cardiopulmonary Resuscitation in ICU and (2) To associate factors of Cardiopulmonary Resuscitation with initial success rate in ICU.

Methods: A Retrospective descriptive study with the Data retrieved from Cardiopulmonary Resuscitation charts of adult patients who had cardiac arrest during their stay in ICU between Jan 1, 2013 till Dec 31, 2015.

Results: The overall initial success rate of Cardiopulmonary Resuscitation in adult patients was $30.5 \%$. For adult group (18-65 years) it was found to be $30.4 \%$ and for geriatrics (more than 65 years) it was found to be $30.6 \%$. The factors: Age, Gender, weight, time of arrest, did not show any statistical significant association with the outcome. Initial monitored rhythm showed significant association in the survival status with $\chi^{2}=34.9(P=0.000)$ for adults $\& \chi^{2}=56.8 \quad(P=0.000)$ for geriatrics and Total duration of Cardiopulmonary Resuscitation showed significant difference in the survival with $t(778)=21.4(P=0.000)$ for adults and $t(568)=12.57(P=0.000)$ for geriatrics.

Conclusion: The overall initial success rate of Cardiopulmonary Resuscitation among adult patients in intensive care unit was $30.5 \%$ and there existed an insignificant difference in the total duration of Cardiopulmonary Resuscitation between males and females.

Keywords: Retrospective; Critical care; Time of arrest; CPR; First monitored rhythm

\section{Akram Mohammad Rasheed, Mohammad Faisal Amera, PJ Parameaswari, Owais Sabri Nu'man, Ahmed Moh'd Elhaj and Muteb A Muteb}

Critical Care Department, King Saud Medical City, Saudi Arabia

Corresponding author:

Akram Mohammad Rasheed

झ akram_rasheed6@yahoo.com

Head, Nursing Education \& Development Comittee, Critical care Department, King Saud Medical City, Saudi Arabia.

Tel: $66565200366 / 66114355555 / 3201$

Citation: Rasheed AM, Amera MF, Parameaswari PJ, et al. The Initial Success Rate of Cardiopulmonary Resuscitation and Its Associated Factors among Intensive Care Unit Patients in a Tertiary Hospital in Saudi Arabia. J Intensive \& Crit Care 2016, 2:3.

\section{Introduction}

In 2000 the American Heart Association (AHA) created the National Registry of Cardiopulmonary Resuscitation (NRCPR) as an evidence-based hospital safety program that provides data derived from a multi observational sites [1]. Every year there are 370,000 to 750,000 hospital resuscitation attempts made in United States [2]. The data comprise comprehensive information related to the cardiopulmonary resuscitation (CPR) process, patients' outcome, and characteristics of both the patients and the hospitals. The purpose of the registry data is to provide information that can be used to improve the outcomes of sudden cardiac arrest (SCA) patients and to update the protocol for CPR. Unfortunately, we do not have a similar national or regional data registry program in Kingdom of Saudi Arabia (KSA) or even in Middle East region. Respiratory or Cardiac arrest is not a surprising event in critical care units. A lot of factors had previously shown to predict CPR outcomes, although with different variability of factors and patient populations [3]. Some of these factors include: duration of CPR [4], close monitoring 
and early recognition of initial arrest rhythm [6]; pulse-less electrical activity (PEA) or asystole versus ventricular tachycardia (VT) or ventricular fibrillation (VF) [6, 7] and age of patient [7]. It has been found that for every minute delay in CPR there is approximately 10 percent decrease in chance of survival [8].

The main aims of this study: (1) to determine the initial success rate of CPR in ICU and (2) to associate factors of CPR with initial success rate in ICU.

This research was approved by the IRB committee of our institution (IRB Registration Number with KACST, KSA H-01-R-053).

\section{Setting}

Research was conducted in a tertiary care hospital with 1500 bed capacity in Riyadh, Kingdom of Saudi Arabia. The Intensive Care Unit (ICU) in this hospital has 120 bed capacities and provides care for different categories of critically ill patients who need comprehensive stabilization. Different categories of cases are admitted under a variety of specialties, such as neurosurgery, trauma, medical, surgical, hematology emergencies and others.

Approximately 2 to 3 incidences of Cardiac arrest (CA) occur per day in ICU and the bedside nurse will call for help and initiate resuscitation efforts in collaboration with other team members. As per the AHA guidelines, at the time of CPR, the nurse in charge will be assigned to fill the CPR form and make sure it is completely filled by the end of CPR event and the team leader will verify the CPR record and sign accordingly. All ICU staff are well trained and have a valid (AHA) advanced cardiac life support ( $A C L S)$ provider card as a mandatory requirement for ICU staff.

\section{Methodology}

The present study is a retrospective descriptive design. Data was collected from charts of CPR of adult patients who had cardiac arrest during their stay in ICU between Jan 1, 2013 and Dec 31, 2015.

The CPR charts and records were available in head nurse station after each event. Analyzing these charts for this study was useful in finding the success rate of CPR in the region and various factors associated with CPR outcomes.

Factors associated with CPR outcomes are categorized as pre arrest factors and intra arrest factors. Preliminary analysis of few CPR charts has revealed so many factors to correlate with CPR outcomes. List of factors is not limited to: Gender (male or female), CPR time during day or night (Time of Arrest (TOA)), Total Duration of CPR, first monitored rhythm (initial rhythm), weight of patients and immediate outcome (revived vs. died).

\section{Definitions and Inclusive Criteria}

Cardiac arrest is the cessation of cardiac mechanical activity, confirmed by the absence of a detectable pulse, unresponsiveness and Apnea (or gasping respirations) [9]. Patients who are suffering only from isolated respiratory arrest requiring assisted ventilation without showing loss of a palpable pulse necessitating external cardiac compression were already connected to mechanical ventilator and they were excluded from the study. Advanced CPR or advanced cardiac life support (ACLS) refer to attempts to restore spontaneous circulation with basic CPR plus advanced airway management and ventilation techniques, defibrillation, and intravenous or endotracheal medications [10]. Only Adult patients (equal to or more than 18 years old) were included in the study. All subjects are categorized into two categories; adults (18 years old until 64 years old) and geriatric patients (65 years old and above). Initial Rhythm is defined as the first cardiac rhythm present when a monitor or defibrillator is attached to a patient after a cardiac arrest [9]; it is the first rhythm shown in the cardiac monitor and indicates the start of CPR. Initial rhythms include asystole, pulse-less electrical activity (PEA), Ventricular Tachycardia (VT), Ventricular fibrillation (VF) and bradycardia. Time of Arrest was studied and entered in $24 \mathrm{~h}$ format, total duration of CPR presented in minutes and weight of the patient was measured in kilograms at the time of admission in ICU. The return of spontaneous circulation (ROSC) is determined by the presence of carotid pulse and was the factor to determine immediate success of CPR or else considered as failure.

\section{Statistical Analysis}

IBM SPSS 21 was utilized for the data analysis and the results were presented as Descriptive statistics-frequency, range, percentage, mean, median, standard error and the inferential statistics $-\chi^{2}$ test, Student-t-test, one way ANOVA, Pearson's Coefficient of Correlation with $5 \%$ of type 1 error, $20 \%$ limit of accuracy and $5 \%$ level of significance. The percentage values are given within parentheses.

\section{Results and Discussion}

In this present study we had a sample of 1350 patients, they were grouped as $780(57.8)$ adults \& 570 (42.2) geriatrics for further analysis. Table 1 shows the descriptive statistics for the characteristics under study - gender, time of arrest, initial rhythm, outcome and Figures 1 and $\mathbf{2}$ highlights the duration of CPR with the First monitored rhythm. There were 552 adult males with an average age of 43.3 years; weight of $72.8 \mathrm{~kg}$ and 228 female adults with average age of 46.9 years, weight of 71.3 $\mathrm{kg}, 337$ geriatric males with an average age of 78.6 years; weight of $73.0 \mathrm{~kg}$ and 233 geriatric females with average age of 76.1 years, weight of $71.7 \mathrm{~kg} .552$ adult males had an average total duration of CPR to be $22.5 \mathrm{~min}$ and 228 female adults with 22.3 min, 337 geriatric males had an average total duration of 23.0 and 233 geriatric females with $22.2 \mathrm{~min}$ (Table 1 ).

\section{The immediate CPR outcome (ROSC or No?)}

When reviewing the literature, it was noticed that different instruments or indicators were used to study CPR outcome. Some are measuring direct and initial (immediate) outcome, while others are using the functional outcome after CPR. The Cerebral Performance Category (CPC) score is one of the most widely used instrument to assess functional outcome after cardiac arrest [9]. Because of lack of a tracking system to follow up discharged cases out of ICU, the use of CPC score to measure the success rate for CPR in our institution was not possible. 
Table 1 Descriptive statistics of the patients in ICU.

\begin{tabular}{|c|c|c|c|}
\hline \multirow{2}{*}{ S. NO. } & & ADULTS & GERIATRICS \\
\hline & CHARACTERISTICS & $N(\%)=780(57.8)$ & $N(\%)=570(42.2 \%)$ \\
\hline 1 & $\begin{array}{l}\text { Gender } \\
\text { Male } \\
\text { Female }\end{array}$ & $\begin{array}{l}552(70.8) \\
228(29.2)\end{array}$ & $\begin{array}{l}337(59.1) \\
233(40.9)\end{array}$ \\
\hline 2 & $\begin{array}{c}\text { Time Of Arrest (H:min) } \\
\text { 00:00-05:59 } \\
\text { 06:00-11:59 } \\
\text { 12:00-17:59 } \\
\text { 18:00-23:59 }\end{array}$ & $\begin{array}{l}190(24.4) \\
210(26.9) \\
202(25.9) \\
178(22.8)\end{array}$ & $\begin{array}{l}145(25.4) \\
150(26.3) \\
143(25.1) \\
132(23.2)\end{array}$ \\
\hline 3 & $\begin{array}{l}\text { Initial Rhythm } \\
\text { Bradycardia } \\
\text { Asystole } \\
\text { PEA } \\
\text { VF } \\
\text { VT }\end{array}$ & $\begin{array}{c}340(43.6) \\
361(46.3) \\
30(3.8) \\
43(5.5) \\
6(0.8)\end{array}$ & $\begin{array}{c}233(40.9) \\
263(46.1) \\
19(3.3) \\
49(8.6) \\
6(1.1)\end{array}$ \\
\hline 4 & $\begin{array}{l}\text { Outcome } \\
\text { Died } \\
\text { Revived }\end{array}$ & $\begin{array}{l}542(69.5) \\
238(30.5)\end{array}$ & $\begin{array}{l}396(69.5) \\
174(30.5)\end{array}$ \\
\hline
\end{tabular}

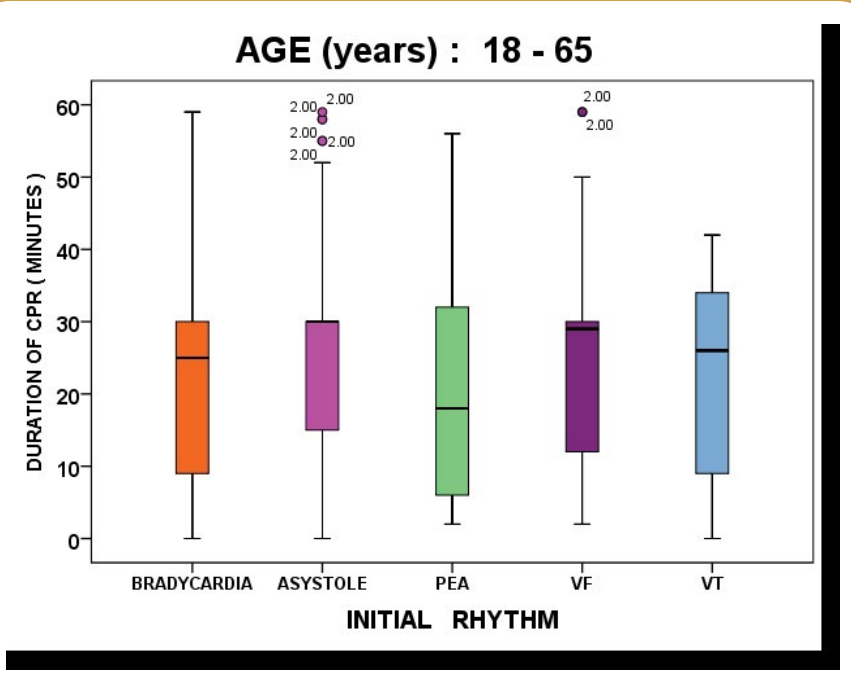

Figure 1 Box plot for the adults.

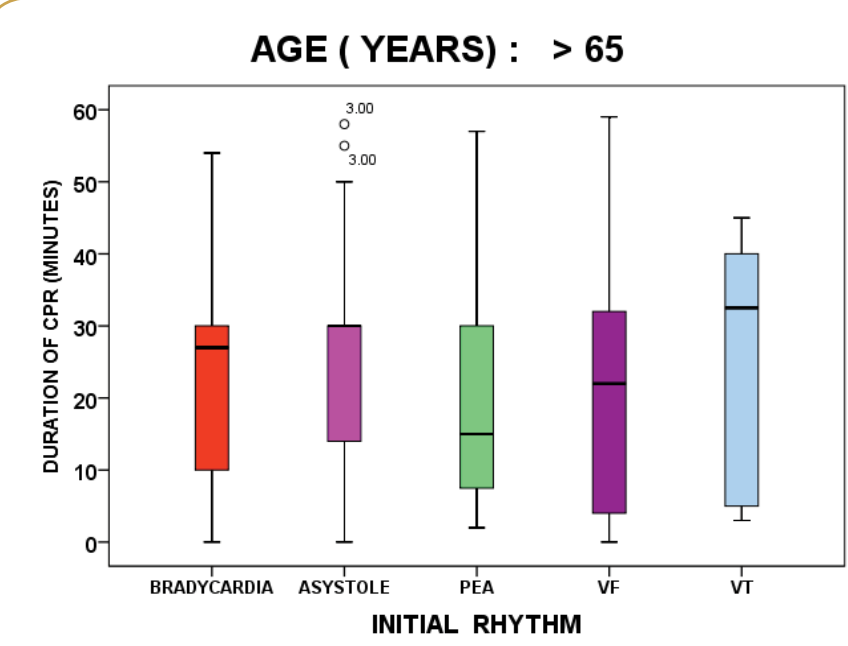

Figure 2 Box plot for the geriatrics.
Instead, we used ROSC as the indictor to measure the success rate of CPR incidence. The results show that the immediate overall success rate of CPR for 1350 patients was $30.50 \%, 95 \%$ confidence interval for the overall success rate of CPR $28.0 \%$ to $32.9 \%$ (for adult group $=30.4 \% 95 \%$ confidence interval is $27.1 \%$ to $33.6 \%$ and geriatric group $=30.6 \%, 95 \%$ confidence interval is $26.8 \%$ to $34.3 \%)$.Other literature is showing variant numbers in regard to immediate CPR outcome, although with variable sample size, setting, and patients background. Some studies have shown the rate of immediate survival as $44 \%, 49 \%, 49.3 \%$, [1113], while other studies had much less rates: $8.3 \%$ to $31.4 \%$ [14] The effect of different factors on immediate success rate of CPR will be discussed later.

Age

Analysis has shown that among total studied records $(N=1350)$, majority are adult patients $(n=780)$ while geriatric patients are less $(n=570)$. The age of adult group $(n=780)$ were ranging from 18 years to 64 years with a mean age of $44.39 \pm 0.46$ years. The age of geriatric group ( $n=570$ ) were ranging from 65 years to 103 years with a mean age of $77.58 \pm 0.41$ years Furthermore, analysis has shown that there is no statistical significant association between age and immediate CPR outcome. Same result was concluded by other articles that reported age did not influence or predict CPR outcome [15-19]. On the other side, few investigators reported that higher age (patients more than 60 year) can predict poor prognosis in CPR $[20,21]$. However, one study had shown that the effect of age on immediate survival rate (ROSC) may be really confusing as real practice of health care providers is showing the trend to provide less aggressive care and less effective (low quality) CPR for old patients during cardiac arrest compared to young adults [22]. Obviously, other articles are concluding the same; the effect of age on survival may be confounded by selection bias: patients aged 70 years or over are less likely to receive CPR than younger persons [23, 24] (Figures 1 and 2).

\section{Gender}

In the present study of $\mathrm{N}=1350$, majority were male patients $n=889(65.8 \%)$ while female patients are less $n=461$ (34.2\%). However, there is no statistically significant association between gender and the parameters-weight, time of arrest, total duration $\&$ immediate survival outcome. This finding is compatible with other studies that they do not document any effect of gender on survival [25]. Few articles showed significant difference between male and females in which females are showing better survival to discharge compared to male patients [26-28].

\section{First monitored rhythm}

Ventricular fibrillation (VF) and ventricular tachycardia (VT) were the least common initially observed rhythm among adults $(5.7 \%)$ and geriatrics (1.0\%). The most common initial observed rhythm was asystole $(46.2 \%)$, followed by bradycardia $(42.3 \%)$. This finding is consistent with other literature that is showing VF/VT as the least monitored initial rhythm $[29,30]$. The high prevalence of asystole rhythm as the initial observed rhythm in comparison to VF/VT can be explained by differences in pathophysiology: in 
hospital cardiac arrest is frequently precipitated by hypoxia or hypotension, which is more likely to cause asystole than VF/VT. Conversely, VF/VT rhythms are more common when ischemia is the precipitating cause of cardiac arrest, as often occurs in out of hospital cardiac arrest [31]. There was a statistically significant association between the initial rhythm and outcome for both adult chi square $=34.9(p=0.0000)$ and geriatric group, chi square $=56.8(p=0.0000)$.

However, the one way ANOVA did not show statistical significance between the initial rhythm in young adult group and old adult group for variables (weight, time of arrest and total duration of CPR).

\section{Total duration}

The average total duration of CPR events for male adult was 22:54 \pm 0.34 , female adult, 22:31 \pm 0.49 , male geriatric 23:00 \pm 0.45 and female geriatric 22:29 \pm 0.51 respectively and an insignificant difference between males and females. Student-t-test showed high significant difference in total duration of arrest between the survival outcome in both adult $t(778)=21.4(P=0.000)$ and geriatric t $(568)=12.57 \quad(P=0.000)$ respectively. However, the relation between total duration and survival outcome should be further investigated. Some findings were reported by other researchers that longer duration resuscitation is associated with worse outcomes than shorter ones $[12,30]$, this can be explained by pathophysiology, in which longer CPR events are associated with vital tissues hypo perfusion and damage accordingly [32]. On the other hand, few researchers concluded that increased duration of CPR can improve the CPR outcome [33, 34].

\section{Time of arrest}

The results had shown that there is no statistical significant association between time of arrest and survival outcome. This can be explained by high monitoring facility in ICU $24 / 7$, in which all patient are continuously connected to cardiac monitors and all cardiac arrests are witnessed. Only few studies had investigated the time of arrest as a predictor to survival rate, however, one of the studies found survival rates from in-hospital cardiac arrest are lower during nights compared to day time, even when adjusted for potentially confounding patient, event, and hospital characteristics [35]. Another study showed that in-hospital cardiac arrest occurring at night had a less favorable neurological outcome than during day time [36].

\section{Weight}

The weight was ranging from 30 to $178 \mathrm{~kg}$ with a mean 72.4 $\pm 0.54 \mathrm{~kg}$ for adult group and 40 to $166 \mathrm{~kg}$ with a mean $72.5 \pm$ $0.60 \mathrm{~kg}$ for geriatric group. However, there was no statistical significant difference between weights of survival outcome. Only few articles had discussed the correlation of weight (or Body Mass Index) with CPR survival outcome, concluding that there is no relation between both parameters $[37,38]$.

\section{Conclusion}

The overall initial success rate of CPR in ICU was 30.5\%, among the adults it was observed to be $30.4 \%$ and for geriatrics $30.6 \%$. The factors Age, Gender, weight, time of arrest, did not show any significant difference in the outcome but, initially monitored rhythm, Total duration of CPR among adults and geriatrics did show significant difference in the survival status. Further analysis is carried out to elicit the relationship of these variables with the success of CPR.

\section{Limitations}

One of the limitations for this study is using the retrospective design. We used the retrospective design because we were using existing data of CPR that have been recorded for three years (Jan 2013 to Dec 2015) to provide convenient large sample of subjects to analyze. However, for future work we do recommend to establish a validated tool to record CPR charts that can be integrated with each event of CPR. This can provide more controlled data to analyze in a prospective feasible design. 


\section{References}

1 Hunt EA, Mancini ME, Smyth M, Truitt TL (2009) Using the American heart association's national registry of cardiopulmonary resuscitation for performance improvement. The Joint Commission Journal on Quality and Patient Safety 35: 13-20.

2 Emmanouel M (2012) In-hospital cardiac arrest. Hospital Chronicles 7: 77-80.

3 Churpek MM, Yuen TC, Huber MT, Park SY, Hall JB, et al. (2012) Predicting cardiac arrest on the wards: A nested case-control study. Chest 141: 1170-1176.

4 Peterson MW, Geist LJ, Schwartz DA, Konicek S, Moseley PL (1991) Outcome after cardiopulmonary resuscitation in a medical intensive care unit. Chest 100: 168-174.

5 Enohumah KO, Moerer O, Kirmse C, Bahr J, Neumann P, et al. (2006) Outcome of cardiopulmonary resuscitation in intensive care units in a university hospital. Resuscitation 71: 161-170.

6 Meaney PA, Nadkarni VM, Kern KB, Indik JH, Halperin HR, et al. (2010) Rhythms and outcomes of adult in-hospital cardiac arrest. Crit Care Med 38: 101-108.

7 Nadkarni VM, Larkin GL, Peberdy MA, Carey SM, Kaye W, et al. (2006) First documented rhythm and clinical outcome from in-hospital cardiac arrest among children and adults. Journal of the American Medical Association 295: 50-57.

8 American Heart Association (2005) American heart association guidelines for cardiopulmonary resuscitation and emergency cardiovascular care. Circulation Supplement 112: IV1-IV211.

9 Cummins RO, Chamberlain DA, Abramson NS, Allen M, Baskett PJ, et al. (1991) Recommended guidelines for uniform reporting of data from out-of-hospital cardiac arrest: the Utstein style. A statement for health professionals from a task force of the American heart association, the European resuscitation council, the heart and stroke foundation of Canada and the Australian resuscitation council. Circulation 84: 960-975.

10 Ajam K, Gold LS, Beck SS, Damon S, Phelps R, et al. (2011) Reliability of the cerebral performance category to classify neurological status among survivors of ventricular fibrillation arrest: a cohort study. Scandinavian Journal of Trauma, Resuscitation and Emergency Medicine 19: 38.

11 Peberdy MA, Kaye W, Ornato JP, Larkin GL, Nadkarni V, et al. (2003) Cardiopulmonary resuscitation of adults in the hospital: A report of 14720 cardiac arrests from the national registry of cardiopulmonary resuscitation. Resuscitation 58: 297-308.

12 Hyeong-Joong Y, Young-Soo K, Yong K, Suck-Jun O, Kwang-Myung K, et al. (2006) Factors associated with survival and neurological outcome after cardiopulmonary resuscitation of neurosurgical intensive care unit patients. Neurosurgery 59: 838-846.

13 Pembeci K, Yildirim A, Turan E, Buget M, Camci E, et al. (2006) Assessment of the success of cardiopulmonary resuscitation attempts performed in a Turkish university hospital. Resuscitation 68: 221-229.

14 Merchant RM, Berg RA, Yang L, Becker LB, Groeneveld PW, et al. (2014) Hospital variation in survival after in-hospital cardiac arrest. J Am Heart Assoc 3: e000400.

15 Rozenbaum EA, Shenkman L (1988) Predicting outcome of in hospital cardiopulmonary resuscitation. Crit Care Med 16: 583-586.
16 Wei-Ren L, Shou-Chuan S, Chien-Liang W, Ming-Jen P, Cheng-Ho T (2012) Age alone may not predict immediate survival outcome in sudden and unexpected in-hospital cardiac arrest. International Journal of Gerontology 6: 196-200.

17 Cohn EB, Lefevre F, Yarnold PR, Arron MJ, Martin GJ (1993) Predicting survival from in-hospital CPR: meta-analysis and validation of a prediction model. J Gen Intern Med 8: 347-353.

18 Wuerz RC, Holliman CJ, Meador SA, Swope GE, Balogh R (1995) Effect of age on prehospital cardiac resuscitation outcome. Am J Emerg Med 13: 389-391.

19 Mullie A, Lewi P, Van Hoeyweghen R (1989) Pre-CPR conditions and the final outcome of CPR. The Cerebral Resuscitation Study Group. Resuscitation 17: S11-S21.

20 Schultz SC, Cullinane DC, Pasquale MD, Magnant C, Evans SRT (1996) Predicting in-hospital mortality during cardiopulmonary resuscitation. Resuscitation 33: 13-17.

21 Herlitz J, Bang A, Gunnarsson J, Engdahl J, Karlson BW, et al. (2003) Factors associated with survival to hospital discharge among patients hospitalized alive after out of hospital cardiac arrest: Change in outcome over 20 years in the community of Göteborg, Sweden. Heart 89: 25-30.

22 Hamel MB, Lynn J, Teno JM, Covinsky KE, Wu AW, et al. (2000) Agerelated differences in care preferences, treatment decisions, and clinical outcomes of seriously ill hospitalized adults: Lessons from SUPPORT. Journal of American Geriatric Society 48: 176-182.

23 Schwenzer KJ, Smith WT, Durbin CG Jr (1993) Selective application of cardiopulmonary resuscitation improves survival rates. Anesthesia Analgesia 76: 478-484.

24 Boyd K, Teres D, Rapoport J, Lemeshow S (1996) The relationship between age and the use of DNR orders in critical care patients. Evidence for age discrimination. Arch Intern Med 156: 1821-1826.

25 Davis DP, Graham PG, Husa RD, Lawrence B, Minokadeh A, et al. (2008) A performance improvement-based resuscitation program reduces arrest incidence and increases survival from in-hospital cardiac arrest. Resuscitation 92: 63-69.

26 Herlitz J, Rundqvist S, Bång A, Aune S, Lundström G, et al. (2001) Is there a difference between women and men in characteristics and outcome after in hospital cardiac arrest? Resuscitation 49: 15-23.

27 Perers E, Abrahamsson P, Bång A, Engdahl J, Lindqvist J, et al. (1999) There is a difference in characteristics and outcome between women and men who suffer out of hospital cardiac arrest. Resuscitation 40 : 133-140.

28 Herlitz J, Engdahl J, Svensson L, Young M, Angquist KA, et al. (2004) Is female sex associated with increased survival after out-of-hospital cardiac arrest? Resuscitation 60: 197-203.

29 Jerry PN, Jasmeet S, David AZ, Dominique B, Leo LB, et al. (2010) European Resuscitation Council Guidelines for Resuscitation 2010 Section 1, Executive summary. Resuscitation 81: 1219-1276.

30 Nadkarni VM, Larkin GL, Peberdy MA, Carey SM, Kaye W, et al. (2006) First documented rhythm and clinical outcome from in-hospital cardiac arrest among children and adults. JAMA 295: 50-57.

31 Cooper S, Janghorbani M, Cooper G (2006) A decade of in-hospital resuscitation: Outcomes and prediction of survival? Resuscitation 68: 231-237. 
32 Sandroni C, Nolan J, Cavallaro F, Antonelli M (2007) In-hospital cardiac arrest: incidence, prognosis and possible measures to improve survival. Intensive Care Med 33: 237-245.

33 Goldberger ZD, Chan PS, Berg RA, Kronick SL, Cooke CR, et al. (2012) Duration of resuscitation efforts and survival after in-hospital cardiac arrest: An observational study. Lancet 380: 1473-1481.

34 Cha WC, Lee EJ, Hwang SS (2015) The duration of cardiopulmonary resuscitation in emergency departments after out-of-hospital cardiac arrest is associated with the outcome: A nationwide observational study. Resuscitation 96: 323-327.

35 Peberdy MA, Ornato JP, Larkin GL, Braithwaite RS, Kashner TM, et al. (2008) Survival from in-hospital cardiac arrest during nights and weekends. JAMA 299: 785-792.

36 Marengo L, Ummenhofer W, Gerster P, Harm F, Lüthy M, et al. (2015) Night time in-hospital cardiac arrest impairs good neurological survival in a Swiss teaching hospital. Circulation 132: A17821.

37 Lutchmedial S, Levitov A, Katyal P, John J, Herbertson R, et al. (2010) In-Hospital cardiopulmonary arrest: the role of $\mathrm{BMI}$, central venous catheter and other predictors of outcome. Am J Respiratory Critical Care Medicine 181: A4544.

38 Jain R, Nallamothu BK, Chan PS (2010) Body mass index and survival after in-hospital cardiac arrest. Circulation: Cardiovascular Quality and Outcomes 3: 490-497. 